\title{
Journal of Thermal Spray Technology Volume 18 Best Paper Awards
}

The Journal of Thermal Spray Technology (JTST) is delighted to announce the winners of the JTST Volume 18 Best Papers Awards, as chosen by an international committee of expert judges. The awards were presented to the winning authors at the International Thermal Spray Conference \& Exposition 2010, in Singapore.

The Editorial Committee and International Board of Review of the journal believe it is important to evaluate the quality of engineering and scientific contributions published in JTST and to provide recognition of excellent work and its publication. Each paper is reviewed and evaluated on its merits for scientific and engineering content, originality, and presentation style. The following papers are recognized as outstanding and the authors received awards of recognition for their excellent publications:

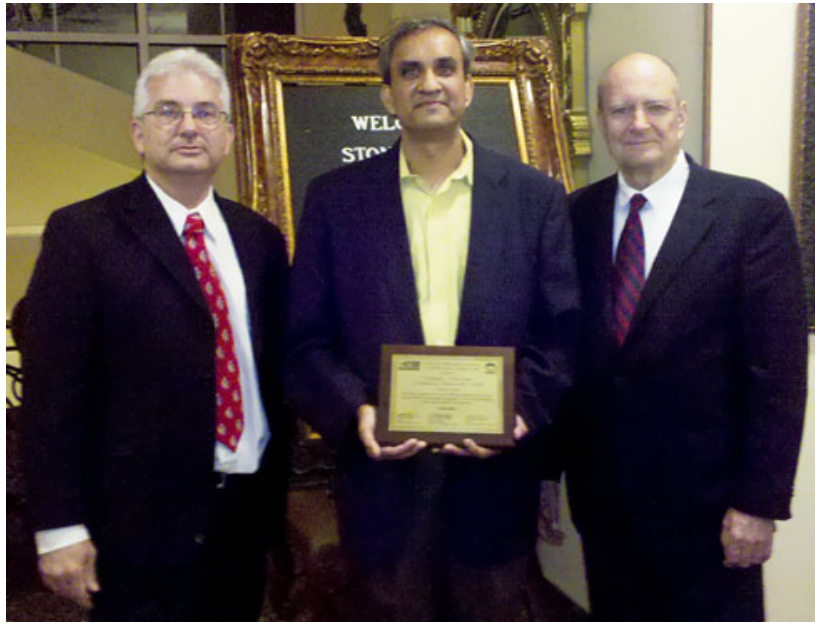

TSS President Mitch Dorfman (left) and Dr. John Marburger III (right), vice president for research, Stony Brook University, congratulated Prof. Sanjay Sampath (center) for receiving the JTST Volume 18 Best Paper Award. Prof. Sampath, Center for Thermal Spray Research, Stony Brook University, coauthored the paper "Sensing, Control, and In Situ Measurement of Coating Properties: An Integrated Approach Toward Establishing Process-Property Correlations" with Vasudevan Srinivasan, Alfredo Valarezo, Anirudha Vaidya, and Tilo Streibl.

\section{The Journal of Thermal Spray Technology Volume 18 Best Paper Award:}

"Sensing, Control, and In Situ Measurement of Coating Properties: An Integrated Approach Toward Establishing Process-Property Correlations" by Sanjay Sampath, Vasudevan Srinivasan, Alfredo Valarezo, Anirudha Vaidya, and Tilo Streibl, Center for Thermal Spray Research, Stony Brook University

\section{The Journal of Thermal Spray Technology Volume 18 Best Paper Honorable Mention Award:}

"Elastic and Conductive Properties of Plasma-Sprayed Ceramic Coatings in Relation to Their Microstructure: An Overview" by Igor Sevostianov, New Mexico State University, and Mark Kachanov, Tufts University

The international committee of judges, led by Dr. Roland Seals, chair of the Journal of Thermal Spray Technology Best Paper Subcommittee, is as follows:

Arvind Agarwal, David V. Bucci, Andrew Gouldstone, David Hart, Jan Ilavsky, Bertrand Jodoin, George Kim, Jiri Matejicek, Tim McKechnie, James Rudd, Roland Seals, Philip Shipway, Yoshiki Tsunekawa, Anirudha Vaidya, Joel Voyer, and Petri Vuoristo.

Congratulations are extended to the winning authors from the JTST Editorial Board and the ASM Thermal Spray Society Executive Board of Directors. 